\title{
MC CDMA PERFORMANCE ON SINGLE RELAY COOPERATIVE SYSTEM BY DIVERSITY TECHNIQUE IN RAYLEIGH FADING CHANNEL
}

\author{
Gelar Budiman ${ }^{1}$, Ali Muayyadi ${ }^{2}$ and Rina Pudji Astuti ${ }^{3}$ \\ ${ }^{1}$ Electrical Engineering Faculty, Telkom University, Bandung, Indonesia \\ gelarbudiman@telkomuniversity.ac.id \\ ${ }^{2}$ Electrical Engineering Faculty, Telkom University, Bandung, Indonesia \\ alimuayyadi@telkomuniversity.ac.id \\ ${ }^{3}$ Electrical Engineering Faculty, Telkom University, Bandung, Indonesia \\ rinapudjiastuti@telkomuniversity.ac.id
}

\begin{abstract}
Wireless communication now has been focus to increase data rate and high performance. The multi carrier on multi-hop communication system using relay's diversity technique which is supported by a reliable coding is a system that may give high performance.

This research is developing a model of multi carrier CDMA on multi hop communication system with diversity technique which is using Alamouti codes in Rayleigh fading channel. By Alamouti research, Space Time Block Code (STBC) for MIMO system can perform high quality signal at the receiver in the Rayleigh fading channel and the noisy system. In this research, $M I M O$ by STBC is applied to single antenna system (Distributed-STBC/DSTBC) with multi carrier CDMA on multi hop wireless communication system (relay diversity) which is able to reduce the complexity of the system but the system performance even can be maintained and improved.

MC CDMA on multi hop wireless communication system with 2 hops is performing much better than Single Input Single Output (SISO) system (1 hop system). Power needed for 1 hop system to have the same quality as 2 hops system to reach BER $10^{-3}$ is $12 \mathrm{~dB}$. And multi hop system needs orthogonal symbol to send from relay than original symbol to reach better performance. 12.5 $d B$ power up is needed for multi hop system which sent same symbol as transmitter than relay system which sent orthogonal symbol.
\end{abstract}

\section{KEYWORDS}

Alamouti, MIMO, multi carier, CDMA, MC CDMA, STBC, Distributed-STBC/DSTBC, diversity, Rayleigh fading, multi-hop system, SISO, relay's diversity

\section{INTRODUCTION}

Wireless communication system development nowadays focused to support the services with high data rate for some the contents of multimedia such as sound, images, data and video. Moreover, the transmitted data is expected to have the better quality with a low bit error rate. To provide the interactive multimedia services, it needs a large bandwidth. However, the available bandwidth is

Natarajan Meghanathan et al. (Eds) : NeTCoM, CSIT, GRAPH-HOC, SPTM - 2014

pp. 27-39, 2014. (C) CS \& IT-CSCP 2014

DOI : $10.5121 /$ csit.2014.41303 
limited, and the wireless communication system has more complex channel characteristic than wireline.

To improve the performance of the wireless system, there should be improvement of coding scheme in the transmitter and receiver. One of them is to apply the code block in multi antenna systems, known as Multiple Input Multiple Output (MIMO). One of MIMO transmission techniques often used is Space Time Block Code (STBC) found by Siavash M. Alamouti [1]. STBC is a such technique that relies on code orthogonality, so the correlation between the antennas would be very small and has an impact to perform better quality than the system without using STBC [1].

The application of STBC was not only good for the multi-antenna system or MIMO, but also the application of STBC in the cooperative communications with multi hop can improve the system transmission performance significantly even with single-antenna [2]. The application of STBC cooperative communications is called the Distributed-STBC (DSTBC). In this research, DSTBC applied to cooperative communication with single antenna on the Rayleigh fading channels and used 2 hops for the simulation.

\section{BASIC THEORY}

\subsection{Basic Concept of Multi Input Multi Output System (MIMO)}

MIMO system is a transmission system (Tx-Rx) where the number of antenna either transmitter or receiver consists of several antenna. Many coding scheme has been performed at MIMO system to get better received signal quality. Alamouti codes is one of the coding scheme to apply at MIMO system which perform good quality.

\subsection{Diversity with Space Time Block Code (STBC)}

Orthogonal space time block code is transmission scheme introduced by Alamouti. Alamouti has introduced coding scheme for $2 \times 2$ or $2 \times 1$ antenna which is shown at figure 2.1 [6].

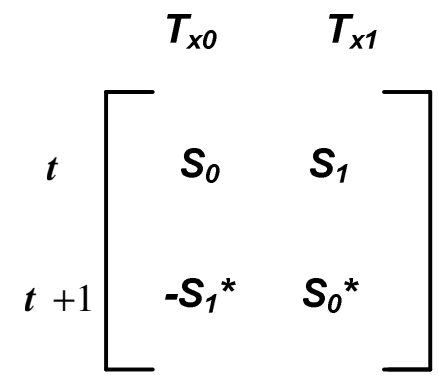

Figure 2.1: Orthogonal Space Time Block Code transmission scheme [1] 


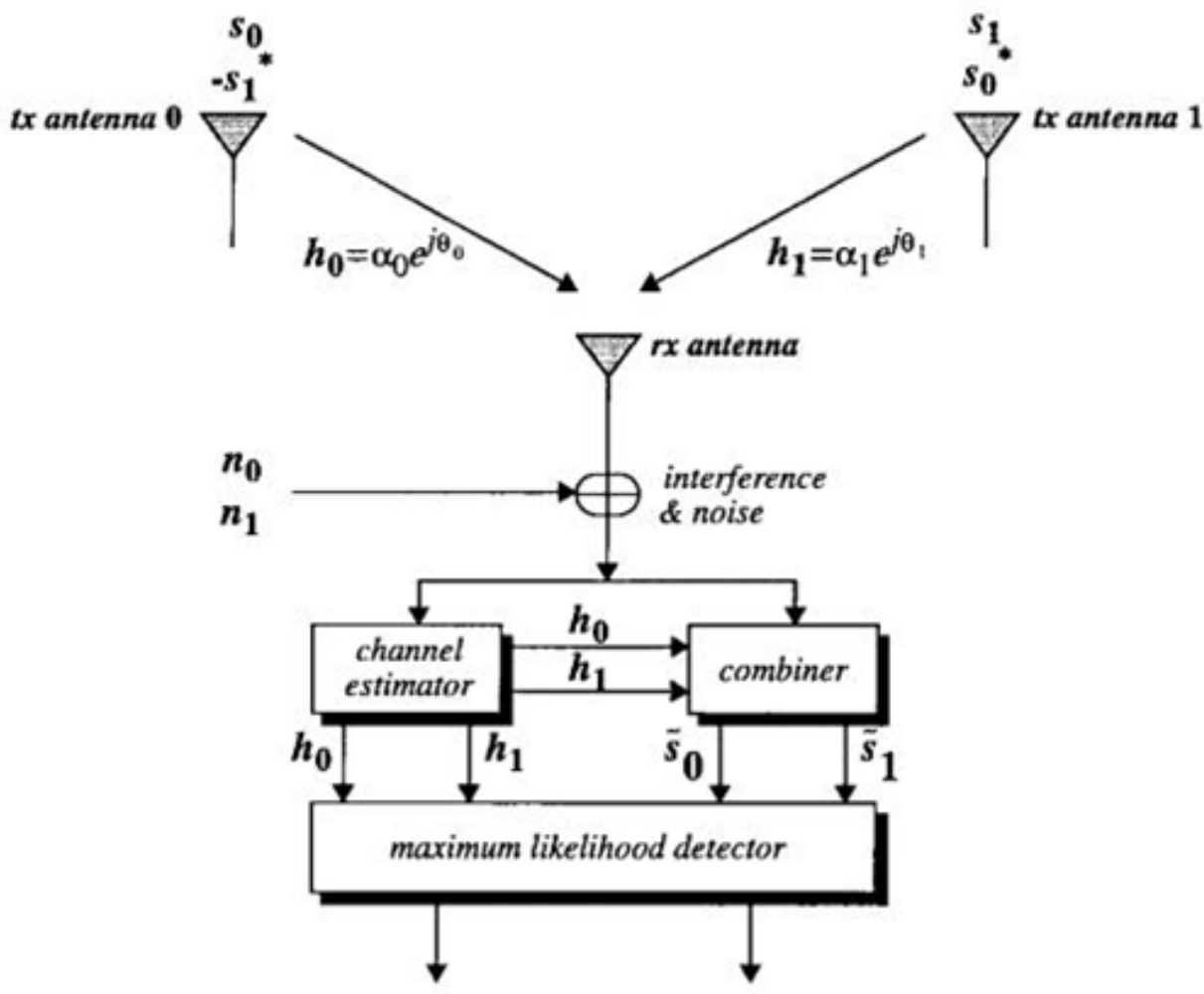

Figure 2.2: MIMO scheme with 2 Tx Antenna and 1 Rx Antenna (2x1) [1]

The channel at time $t$ is modelled by a complex multiplicative coefficient $\boldsymbol{h}_{0}(t)$ from $1^{\text {st }}$ transmitter antenna and $\boldsymbol{h}_{\boldsymbol{l}}(t)$ from $2^{\text {nd }}$ transmitter antenna. Assuming that fading coefficients are constant across two consecutive symbols as [1]:

$$
\begin{aligned}
& h_{0}(t)=h_{0}(t+T)=h_{0}=\alpha_{0} e^{j \theta_{0}} \\
& h_{1}(t)=h_{1}(t+T)=h_{1}=\alpha_{1} e^{j \theta_{1}}
\end{aligned}
$$

According to figure 2.1 and figure 2.2 , the equation of received signal is [1]:

$$
\begin{gathered}
r_{0}=r(t)=h_{0} s_{0}+h_{1} s_{1}+n_{0} \\
r_{1}=r(t+T)=-h_{0} s_{i}^{*}+h_{1} s_{0}^{*}+n_{1}
\end{gathered}
$$

$\boldsymbol{n}_{\boldsymbol{0}}$ and $\boldsymbol{n}_{1}$ are complex random variable which representates interference and noise thermal. Combiner subsystem in figure 2 will decode received signal by maximum likelihood formula as [1]:

$$
\begin{aligned}
& \tilde{s}_{0}=h_{0}^{*} r_{0}+h_{1} r_{i}^{*} \\
& \tilde{s}_{1}=h_{1}^{*} r_{0}-h_{0} r_{i}
\end{aligned}
$$




\begin{tabular}{c|c|c}
\cline { 2 - 3 } & antenna 0 & antenna 1 \\
\hline time $t$ & $s_{0}$ & $s_{1}$ \\
\hline time $t+T$ & $-s_{1}^{*}$ & $s_{0}{ }^{*}$ \\
\hline
\end{tabular}

Figure 2.3 : Received Signal Notation In Scheme 2x1 [1]

Substituting equation 2.1 to 2.3 will make a result [1]:

$$
\begin{gathered}
\tilde{s}_{0}=\left(\alpha_{0}^{2}+\alpha_{1}^{2}\right) s_{0}+h_{0}^{*} n_{0}+h_{1} n_{1}^{*} \\
\tilde{s}_{1}=\left(\alpha_{0}^{2}+\alpha_{1}^{2}\right) s_{1}-h_{0} n_{1}^{*}+h_{1}^{*} n_{0}
\end{gathered}
$$

\subsection{Diversity by Distributed Space Time Block Code (DSTBC)}

The application of STBC was not only good for the multi-antenna system or MIMO, but also for cooperative communications with multi hop system. It can improve the system transmission performance significantly even with single-antenna [2]. The application of STBC cooperative communication is called the Distributed-STBC (DSTBC). The system scenario is described as the situation displayed in figure 2.4.

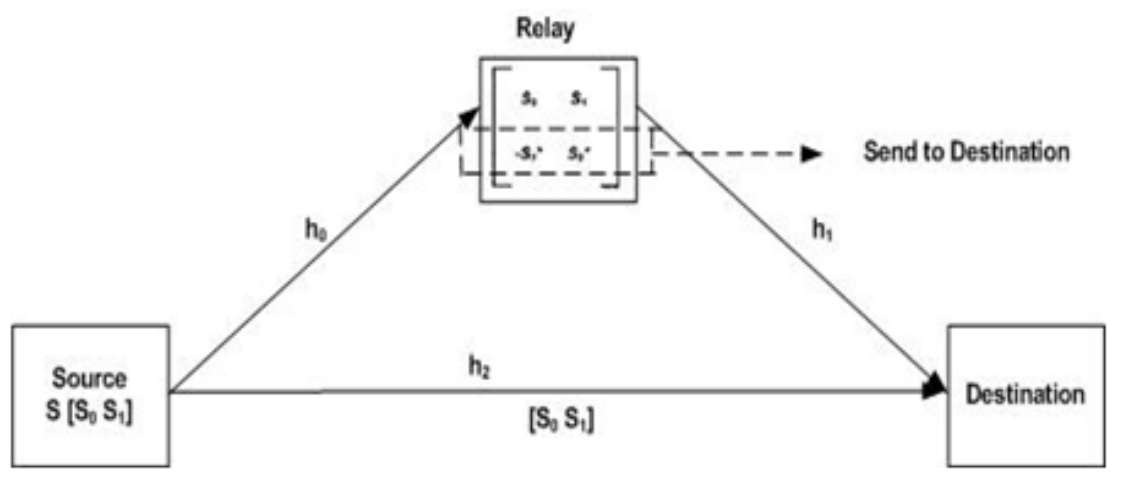

Figure 2.4 : Transmission scheme based of relay technique [3] [4]

According to figure 2.4, the equation of received signal is :

$$
\begin{aligned}
& r_{1}=-s_{2}^{*} h_{1}+s_{1} h_{2} \\
& r_{2}=s_{1} h_{2}+s_{2} h_{3}
\end{aligned}
$$

Combiner block in figure 2.4 makes two signals below which will be transmitted to maximum likelihood detector :

$$
\begin{gathered}
\tilde{s}_{1}=r_{1} h_{3}^{*}+h_{2} r_{2}^{*} \\
\tilde{s}_{2}=-h_{2} r_{1}^{*}+h_{3} r_{2}^{*}
\end{gathered}
$$




\subsection{Transmission Channel Decoding}

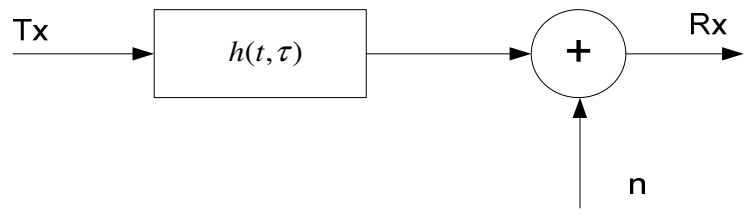

Figure 2.5 : General Channel Model [5]

A transmission channel generally can be defined:

$h(t, \tau)$ is time varying impulse response from multipath channel, mathematically it's defined as [5]:

$$
\begin{gathered}
h(t, \tau)=\sum_{i=0}^{N-1}\left\{a_{i}\left(t, \tau_{i}(t)\right) p\left(t, \tau_{i}(t)\right)\right\} \\
p\left(t, \tau_{i}(t)\right)=\mathrm{e}^{j 2 \pi f_{c} \tau_{i}(t)+\theta\left(t, \tau_{i}(t)\right) \delta\left(t-\tau_{i}(t)\right)}
\end{gathered}
$$

where:

- $\quad a_{i}\left(t, \tau_{i}(t)\right)$ is gain from $i$-th multipath component at time $t$.

- $2 \pi f_{c} \tau_{i}(t)+\theta_{i}\left(t, \tau_{i}(t)\right)$ is a term to representate phase shifting because of propagation at $i$-th multipath component.

- $\quad N$ is propagation path number.

Doppler shifting is expressed by equation [2]:

$$
f_{d}=\frac{v}{\lambda} \cos \theta
$$

where :

$v=$ relative movement velocity

$\lambda=$ wavelength of carrier

$\theta=$ angle between incoming signal direction and antenna movement direction

\subsection{Multicarrier Modulation}

Multicarrier modulation is defined as modulation technique in which there are several subcarrier or frequency to modulate the separate signal and every subcarrier is orthogonal each other. This mechanism is also called OFDM (Orthogonal Frequency Division Multiplexing). By this nature the signal in every subcarrier can be overlapped without Intercarrier Interference (ICI). This 
mechanism can save bandwitdh needs [9]. Spectrum illustration between conventional FDM and multicarrier (OFDM) is shown at figure 2.6.

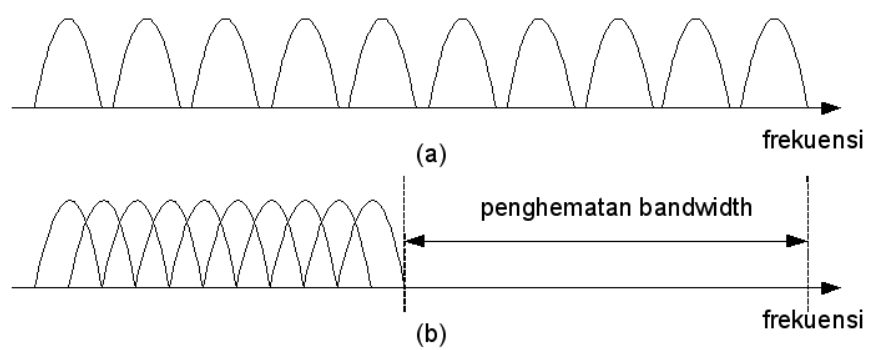

Figure 2.6 : Multi Carrier Spectrum (a) No Overlap (b) Orthogonally Overlap

Mathematically, group of signal $\varphi_{\mathrm{i}}, \mathrm{i}= \pm 0, \pm 1, \pm 2, \ldots .$. akan ortogonal pada interval $[\mathrm{a} b]$, jika :

$$
\begin{gathered}
\int_{a}^{b} \varphi_{l}(t) \varphi_{k}^{*}(t) d t= \begin{cases}E_{k}, & \text { jika } l=k \\
0, & \text { jika } l \neq k\end{cases} \\
=E_{k} \delta(l-k)
\end{gathered}
$$

$E_{k}$ is constant resulting from integration and $\varphi_{k}^{*}(\mathrm{t})$ is conjugate complex from signal $\delta(l-k)$ (delta kronecker) [10], which is defined as :

$$
\delta(l-k)= \begin{cases}1, & \text { when } l=k \\ 0, & \text { when } l \neq k\end{cases}
$$

Basis function Discrete Fourier Transform (DFT) or Fast Fourier Transform is : $\varphi_{k}(t)=e^{[j(2 \pi k t) / T]}$, where $\mathrm{k}=0, \pm 1, \pm 2, \pm 3, \ldots \ldots$ forms group of orthogonal signal at interval $(0$, T) $(T=$ signal periode $)$ :

$$
\begin{aligned}
\int_{0}^{T} \phi_{l}(t) \varphi_{k}^{*}(t) d t & =\int_{0}^{T} \exp \left[\frac{j(2 \pi l t)}{T}\right] \exp \left[\frac{-j(2 \pi k t)}{T}\right] d t \\
& = \begin{cases}T, & \text { jika } l=k \\
0, & \text { jika } l \neq k\end{cases}
\end{aligned}
$$

\section{COOPERATIVE SYSTEM BASED ON ONE RElay MODEL (2 HOPS SYSTEM)}

\subsection{Model System}

The communication between the source and the user not only directly but also through the relay. So that, the received signal is the sum of the user that sent the signal directly (direct channel) and signal through the relay (the relay channel). 


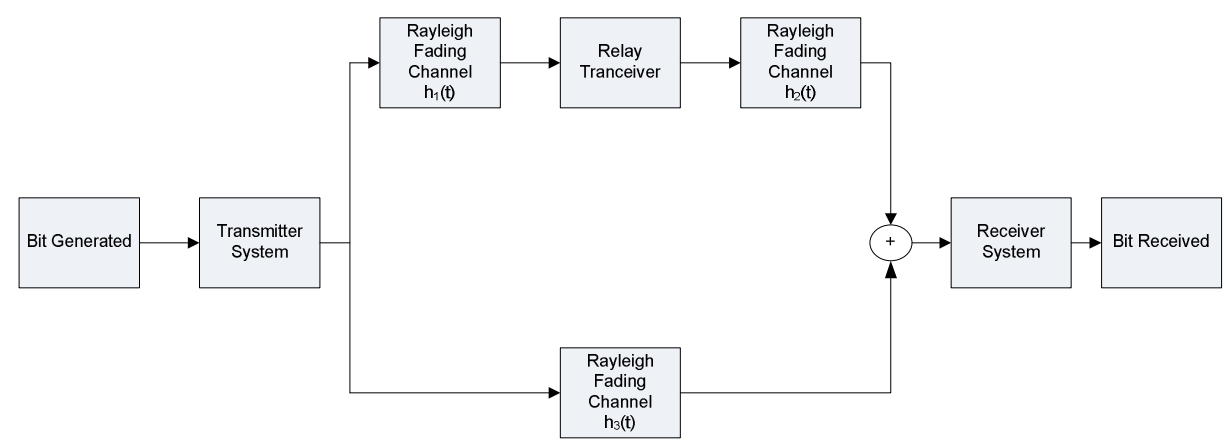

Figure 3.1 : Two Hops System Model with Single Antenna [9]

As shown at figure 3.1 the multi hop system introduced 2 hops, such as : 1 . the hop between base station (BS) and mobile station (MS) via relay, 2. the hop between BS and mobile station (MS) directly without relay. Fading channel distribution realized in 2 hops are Rayleigh fading channel in i.i.d distributed. Because of Rayleigh channel, received signal performance of 2 hops system should be affected by mobility of either relay or MS velocity. Figure 3.2 explained SISO (Single Input Single Output) system model (1 hop system) in which its performance will be compared to 2 hops system performance [9].

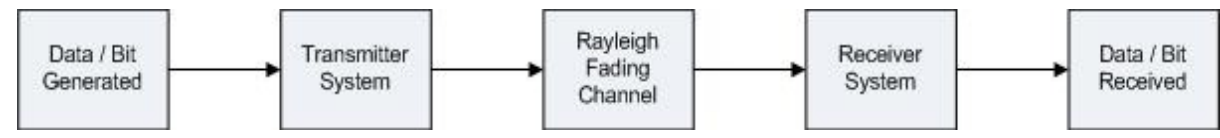

Figure 3.2 : SISO System Model [7]

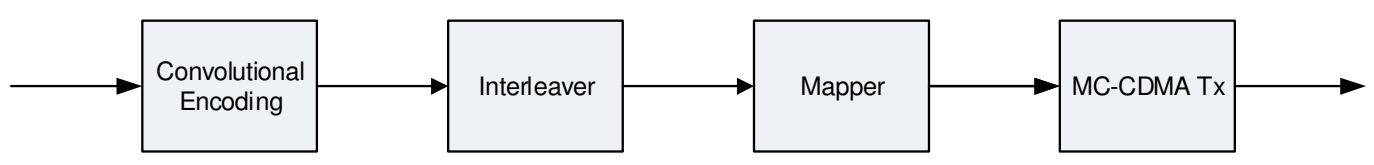

Figure 3.3 : Transmitter System Model

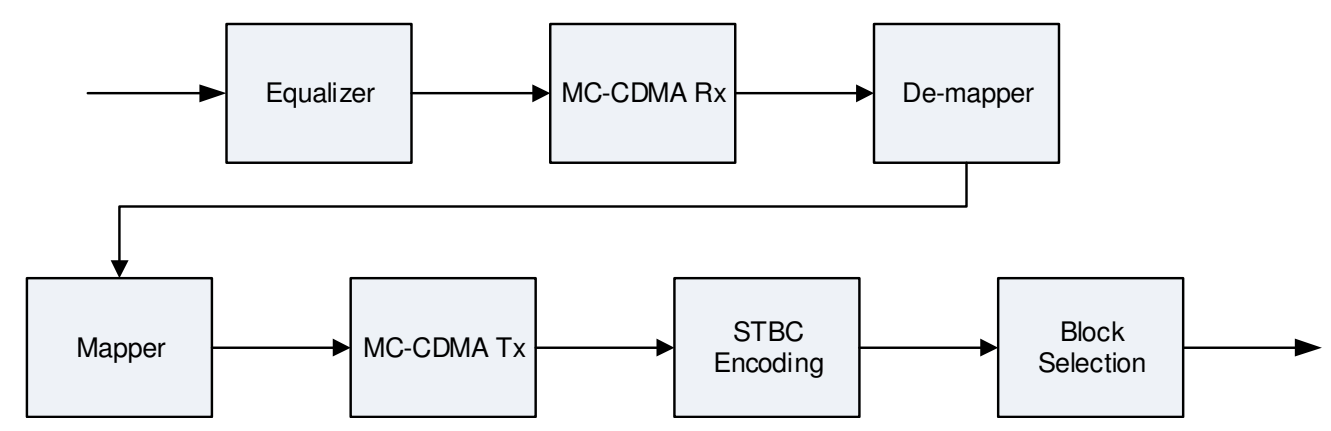

Figure 3.4 : Relay Tranceiver System Model [9]

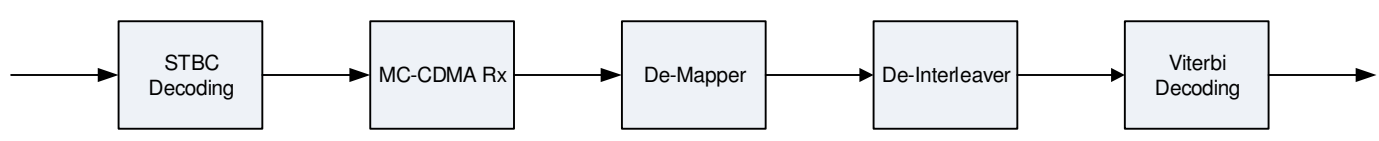

Figure 3.5 : Receiver System Model 
The transmitter system of BS or SISO transmitter consists of 3 subsystems processing baseband signal as shown in figure 3.3. While relay transceiver from figure 3.1 consists of 5 subsystems which equalized, normalized, STBC encoded, and selected one block code before transmitting the signal to MS as shown in figure 3.4. As shown in figure 3.5, receiver system consists of several subsystem which decoded combined signal from BS and relay by Alamouti principal, demodulate, deinterleaved, and Viterbi decoded. Next, the data compared to the original data for counting BER performance.

The content of MC CDMA transmitter by frequency domain spreading is shown in figure 3.6. The content of MC CDMA receiver by frequency domain spreading is shown in figure 3.6.

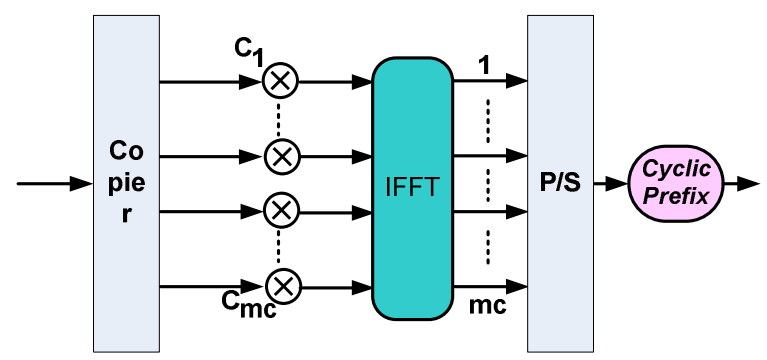

Figure 3.6 : MC CDMA Transmitter Model System [7]

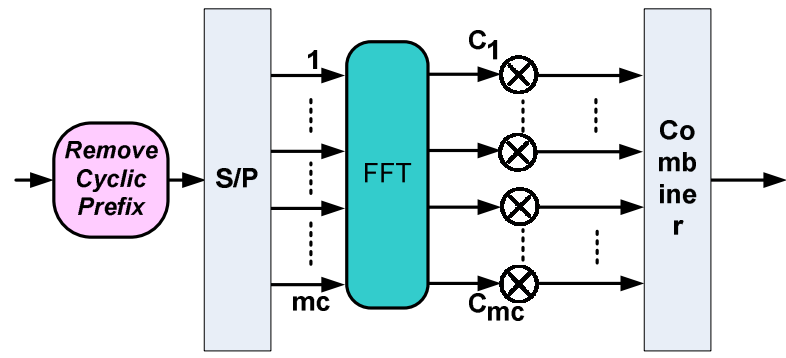

Figure 3.7 : MC CDMA Receiver Model System [7]

The content of MC DS CDMA transmitter by frequency domain spreading is shown in figure 3.8. The content of MC Ds CDMA receiver by time domain spreading is shown in figure 3.9.

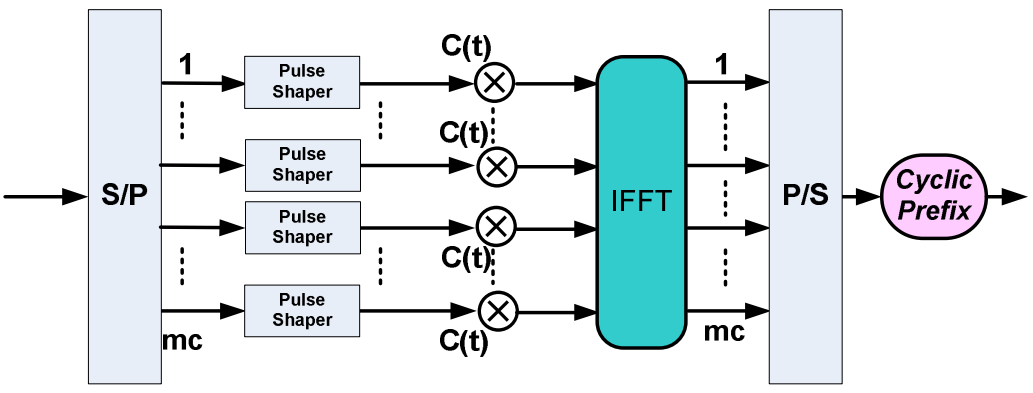

Figure 3.8 : MC DS CDMA Receiver Model System [7] 


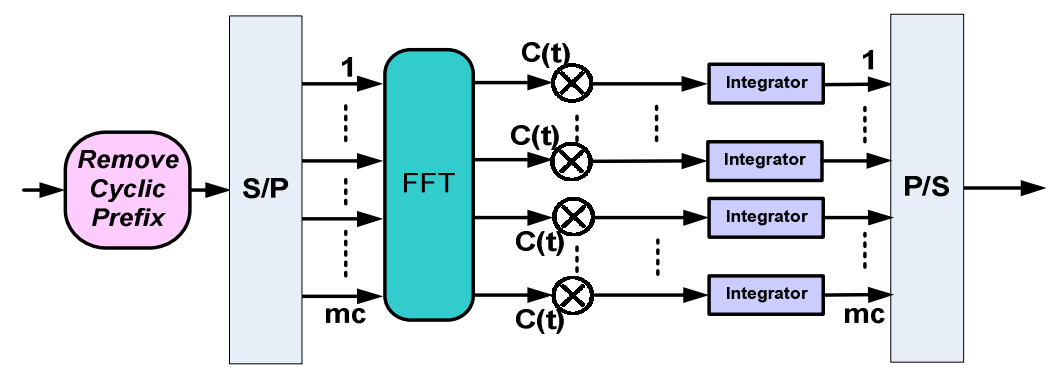

Figure 3.9 : MC DS CDMA Receiver Model System [7]

\section{MC CDMA MULTIHOP COOPERATIVE SYSTEM PERFORMANCE}

This simulation was running by several scenarios, such as :

1. Comparison between SISO, and MC CDMA with multi hop either frequency domain spreading MC CDMA or time domain spreading MC CDMA at flat fading Rayleigh.

2. Perform how much subcarrier number affected the performance of multi hop MC CDMA.

3. Perform how much subcarrier number affected the performance of multi hop MC DS CDMA.

4. Comparison performance between multihop MC CDMA, MC DS CDMA, and SISO on selective frequency Rayleigh fading.

5. Comparison performance of multi hop MC CDMA and MC DS CDMA in the different fading channel condition.

For the first scenario, the parameter implemented in the simulation has following limitation :

- Flat Fading Rayleigh

- 32 spreading code (Walsh-Hadamard)

- MS Velocity $30 \mathrm{~km} / \mathrm{h}$

- QPSK mapper

- Using 32 subcarriers (At Multicarrier system)

- Perfect Channel Estimation

The simulation result is displayed at figure 4.1.

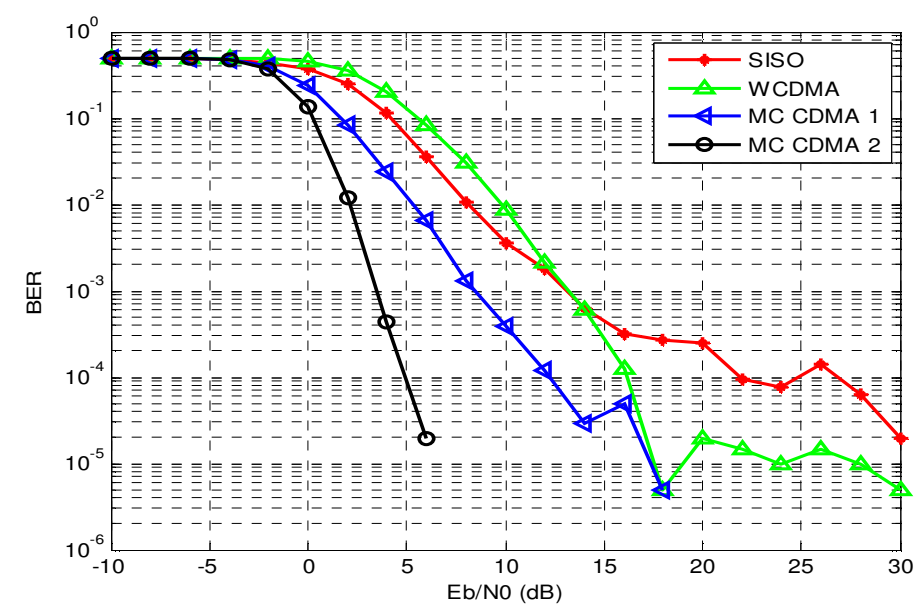

Figure 4.1 : Multi Hop System Performance Comparison 
As displayed in figure 4.1, SISO has better performance when Eb/N0 less than $17 \mathrm{~dB}$, but more than $17 \mathrm{~dB}$ MC DS CDMA started to have better performance than SISO system. MC CDMA started to have better than SISO at Eb/N0 more than $19 \mathrm{~dB}$. At this simulation it is concluded that both MC CDMA in multi hop communication has a worse performance than SISO when Eb/N0 is still below about $18 \mathrm{~dB}$. But more than $18 \mathrm{~dB}$ both MC CDMA has significant performance as the $\mathrm{Eb} / \mathrm{N} 0$ raises.

For the second scenario, simulation testing was done with following parameter :

- Frequency Selective Fading Rayleigh

- 32 spreading code (Walsh-Hadamard)

- MS Velocity $30 \mathrm{~km} / \mathrm{h}$

- BPSK mapper

- Using 32 subcarriers (At Multicarrier system)

- Perfect Channel Estimation

The simulation result is displayed at figure 4.2 and figure 4.3.

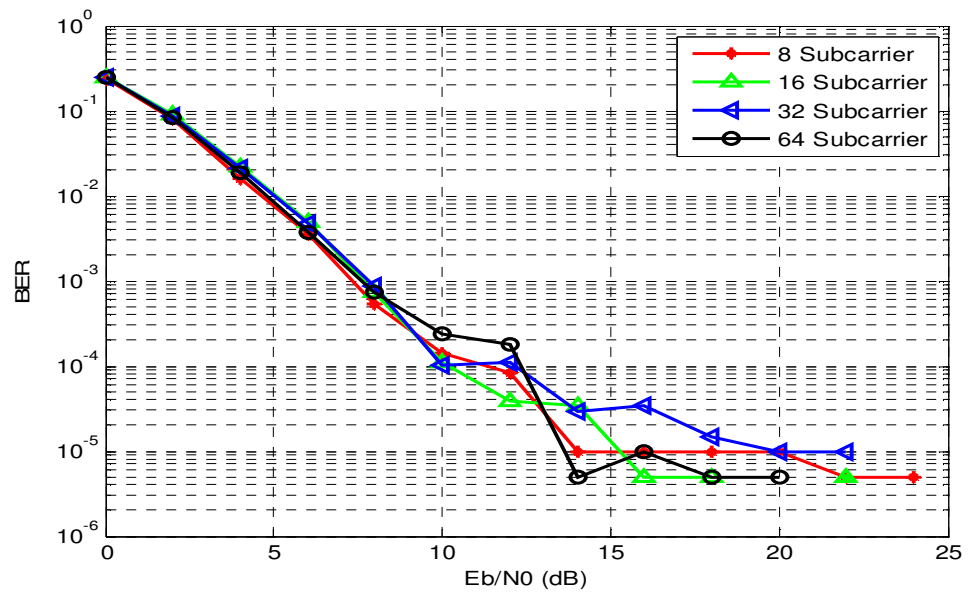

Figure 4.2 : Subcarrier Effect on Multi hop MC CDMA System

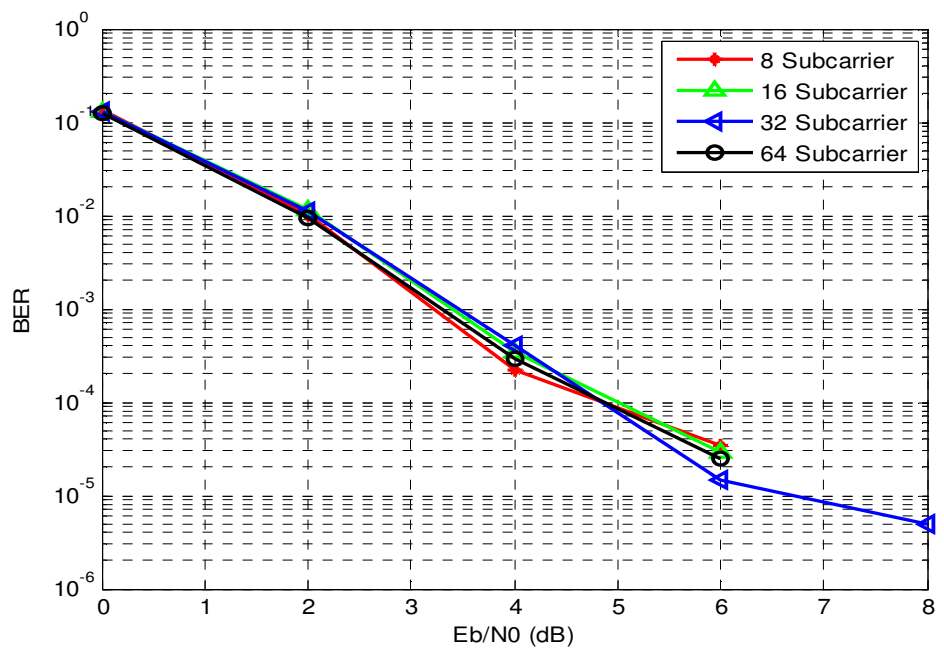

Figure 4.3 : Subcarrier Effect on Multi hop MC DS CDMA System 
For the third scenario, simulation testing was done with following parameter :

- Rayleigh Frequency Selective Fading

- 32 spreading code (Walsh-Hadamard)

- MS Velocity $60 \mathrm{~km} / \mathrm{h}$

- BPSK mapper

- Using 32 subcarriers (at Multicarrier system)

- Perfect Channel Estimation

The simulation result is displayed at figure 4.4.

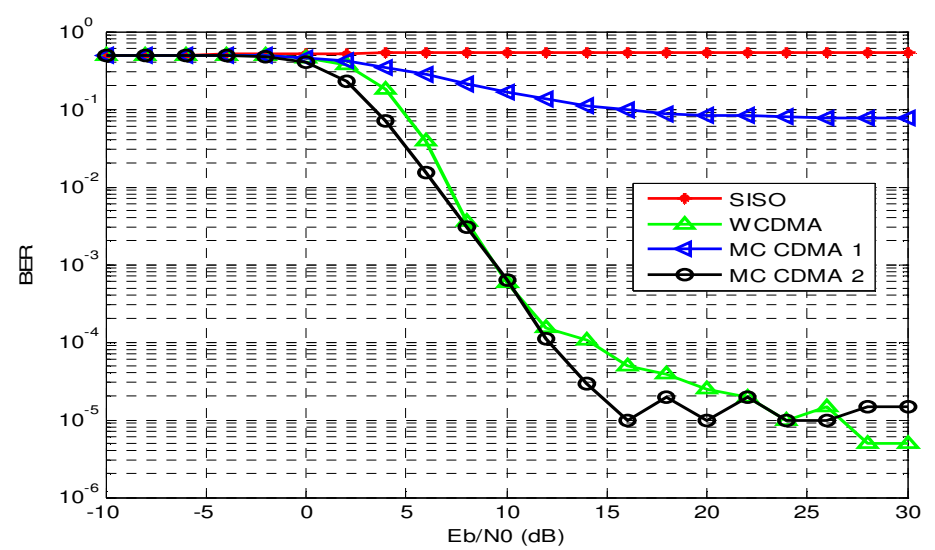

Figure 4.4 : Multihop Performance On Rayleigh Selective Frequency Fading

For the forth scenario, simulation testing was done with following parameter :

- Flat and Frequency Selective on Rayleigh Fading Distribution

- 32 spreading code (Walsh-Hadamard)

- MS Velocity $60 \mathrm{~km} / \mathrm{h}$

- QPSK mapper

- Using 32 subcarriers (At Multicarrier system)

- Perfect Channel Estimation

The simulation result is displayed at figure 4.5.

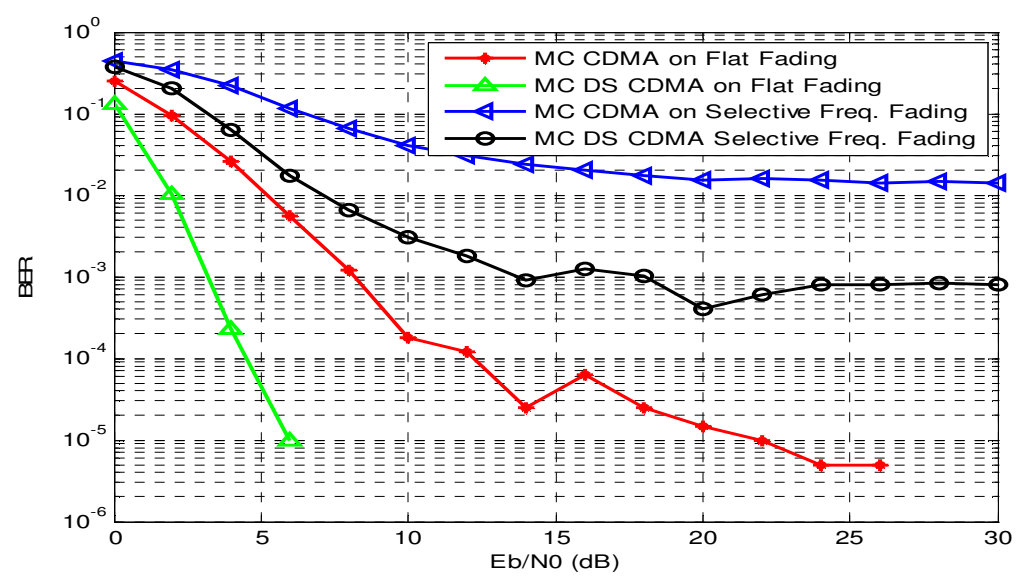

Figure 4.5 : Multihop MC CDMA and MC DS CDMA Performance Comparison On Flat and Frequency Selective Fading 


\section{CONCLUSION}

\subsection{Conclusion \& Suggestion}

1. There will need an improvement formula on MC CDMA Receiver to get better performance. Maximum Likelihood on inner code DSTBC might be improving the performance.

2. Different time symbol received should be simulated and analyzed in the next research as the real condition which needs to be anticipated.

3. Developing system with multi antenna scheme at the transmitter and receiver might perform better performance.

\section{REFERENCES}

[1] Alamouti SM, “A Simple Transmit Diversity Technique for Wireless Communication”, IEEE Journal on Selected Areas in Communication, vol. 16 No.8, October 1998.

[2] Jaafar W., "On the Performance of Distributed-STBC in Multi-hop Wireless Relay Networks", IEEE European Wireless Conference, 2010.

[3] Adi Nugroho,"Analisis Kinerja Sistem Kooperatif Menggunakan Skema Distributed-Alamouti”, Tugas Akhir, ITS, 2010.

[4] Borah D.K, Moreno Crespo, Nammi S., "Distributed Alamouti Transmit Diversity Technique for CoOperative Communication”, Vehicular Technology Conference, 2007. VTC2007-Spring. IEEE 65th, Dublin, 2007.

[5] J. Proakis, "Digital Communications", McGraw Hill, 3rd., 1995.

[6] David Gesbert, Mansoor Shafi, Da-Shan Shiu, Peter J. Smith, Ayman Naguib, "From Theory to Practice : An Overview of MIMO Space-Time Coded Wireless Systems", Tutorial Paper, IEEE Journal On Selected Areas In Communication Vol. 21, No.3 April 2003, Oslo University, Norway.

[7] Gelar Budiman,Suhartono, Rina Pudji Astuti, "Konfigurasi MIMO MC-CDMA Pada Kanal Fading Rayleigh”, Jurnal Telekomunikasi IT Telkom Desember 2007 Volume-12 Nomor 2 Hal. 82-88 ISSN : No. 1410-7066, ITTelkom, 2007.

[8] Nur Andini, Ali Muayyadi, Gelar Budiman, "Analisis Performansi WCDMA Diversitas Relay Pada Kanal Fading”, Prosiding Konferensi Nasional ICT-M Politeknik Telkom (KNIP) ISSN : 2088-8252, Bandung, 2011.

[9] Ali Muayyadi, Gelar Budiman, Rina Pudji Astuti, "The performance analysis of multiuser WCDMA systems using D-STBC in Rayleigh fading channel", Advanced Communication Technology (ICACT), Pages 1213-1216, South Korea, 2014.

\section{AUTHORS}

Gelar Budiman is a lecturer from Electrical Engineering Faculty of Telkom University since 2008. He was graduated from STTTelkom in 2002 as an Electrical Engineering undergraduate student, and same university as Electrical Engineering Master in Telecommunications in 2005. He is an assistant manager of Distance Learning Education Infrastructure in Telkom University, Bandung, Indonesia and has done several researches and lecturer activities such as eLearning grants and community services in relation of his competency. His research competencies are about wireless communication, signal processing, and mobile application.

Ali Muayyadi is a member of IEEE. He finished his BEng degree in electrical engineering from ITB, Bandung, Indonesia in 1990, MSc degree in mobile communicate ons from ENST, Paris in 1997 and $\mathrm{PhD}$ degree in digital communications from University of Plymouth, UK in 2003. Now he is the head of Telecommunication Transmission Expert Group of Electrical Engineering Faculty, Telkom University, Bandung, Indonesia.
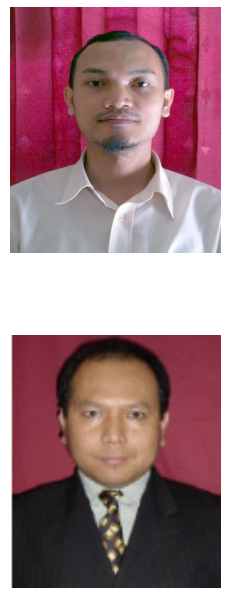
Rina Pudji Astuti is a lecturer in Electrical Engineering Faculty in Telkom University, Bandung, Indonesia. She finished her undergraduate degree from Electrical Engineering ITS in 1987, Surabaya. She was graduated from Electrical Engineering Master degree from ITB, Bandung, Indonesia in 1999, and Doctoral degree from Electrical and Informatics Engineering in 2009 from ITB. Now she is the Dean of Electrical Engineering Faculty, Telkom university, Bandung, Indonesia. Her interest is in Wireless Communication in speciality of $4 \mathrm{G}$ and $5 \mathrm{G}$ Telecommunication Technology.

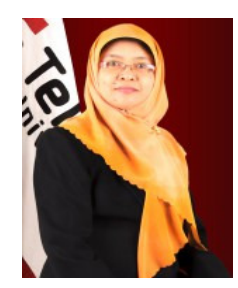

